\title{
Seminal transmission of Lumpy Skin Disease Virus in heifers
}

\author{
C. H. Annandale ${ }^{1}$, D. E. Holm ${ }^{1}$, K. Ebersohn ${ }^{2}$ and E. H. Venter ${ }^{2}$
}

\author{
${ }^{1}$ Department of Production Animal Studies and \\ ${ }^{2}$ Department of Veterinary Tropical Diseases, Faculty of Veterinary Science, University of Pretoria, \\ Onderstepoort, South Africa
}

\section{Summary}

It is known that lumpy skin disease virus (LSDV) can be shed in bull semen following infection and that artificial insemination (Al) poses a biosecurity risk. It is however not known whether the use of LSDV infected semen in Al poses a biosecurity risk. The aims of the current study were to investigate whether LSDV, transmitted through semen, can infect cows and embryos.. Two controlled trials were performed simultaneously. Eleven (11) young beef heifers, naïve to LSDV, were synchronized using an OvSynch protocol and inseminated with fresh semen spiked with a field strain of LSDV on day 0. Six (6) of the heifers were superovulated on Day 1 using PMSG, and embryos were flushed from these heifers on Day 6. Blood and serum samples were collected from Day 4 until Day 27 to determine the presence of LSDV by PCR and virus isolation, and the presence of antibodies against LSDV by SNT.

The first clinical signs of LSD were noticed on Day 10 , followed by severe generalized LSD in 3 heifers, and mild LSD in 2 more heifers. Two heifers were humanely euthanized due to severe unresponsive stranguria. LSDV was detected by PCR, virus isolation or electron microscopy in blood, embryos and organs of experimentally infected animals, and 8 heifers had seroconverted by Day 27. Two control animals were not affected.

This is the first report of experimental seminal transmission of LSDV in cattle.

\section{Keywords}

Lumpy skin disease virus; semen; artificial insemination; embryo; transmission. 


\section{INTRODUCTION}

Lumpy skin disease virus (LSDV), a member of the genus Capripoxvirus within the family Poxviridae, causes an acute to inapparent disease in cattle, characterised by firm, circumscribed skin nodules, necrotic plaques in the mouth and nares, fever and generalized lymphadenopathy (Coetzer, 2004). Through its effect on quality of hides, reduced feed intake, pneumonia and infertility, economic losses associated with the disease can be substantial (Woods, 1988). Although endemic to sub-Saharan Africa, lumpy skin disease (LSD) has the potential to spread to other parts of Africa, the Middle East and Europe (Tuppurainen and Oura, 2012).

A number of possible routes of transmission for LSDV have been investigated and identified. This includes arthropods, biting insects and mosquitoes (Chihota et al., 2001, Chihota et al., 2003, Kitching and Taylor, 1985, Kitching and Mellor, 1986, Carn and Kitching, 1995). The role of ticks in transmission has been suspected (Aiel, 2009) with observations in some outbreaks of the presence of ticks, especially Amblyomma ticks, on affected animals (Ali and Obeid, 1977). A recent study indicated that transstadial and transovarial transmission of LSDV by Rhipicephalus (Boophilus) decoloratus ticks and mechanical or intrastadial transmission by Rhipicephalus appendiculatus and Amblyomma hebraeum ticks was possible (Tuppurainen et al., 2010). The mechanical transmission of LSDV by R. appendiculatus male ticks has also now been confirmed (publication submitted). Recent research has indicated the presence of LSDV in semen and the possible risk of transmission of the disease via this route. In a study by Irons et al. (2005), virus particles were detected in semen of experimentally infected animals for up to 5 months, when clinical signs were no longer evident. Following an initial drastic deterioration in semen quality during the acute phase of the infection, the quality of the semen recovered before the end of the period of virus excretion (Irons et al., 2005). It was also shown that LSDV is not limited to specific fractions of the ejaculate and the testes and the epididymides are most profoundly affected (Annandale et al., 2010). Virus was not thought to be sperm or blood associated and it was concluded that the ejaculate was likely to have been contaminated with virus that was being shed during emission from necrotic lesions in the genital tract (Annandale et al., 2010). The risk posed to in vitro fertilisation (IVF) procedures was also demonstrated. It was established that the virus was sperm-associated in $9 \%$ of spermatozoa and that the early blastocyst contained viral DNA (Irons, 2008). The contradictory finding of sperm association of virus in these two studies needs further investigation to establish the significance thereof.

Transmission through artificial insemination (Al) has been observed in different animal species e.g. for equine arteritis virus (Guthrie et al., 2003), porcine reproductive and 
respiratory syndrome virus (Christopher-Hennings et al., 1995), classical swine fever virus (Smit et al., 1999) and feline immunodeficiency virus (Jordan et al., 1996).

In bovines, foot-and-mouth disease virus and bovine herpesvirus 1 can be transmitted to susceptible heifers by insemination with infected semen (Afshar and Eaglesome, 1990). Intrauterine inoculation with ephemeral fever virus did not result in seroconversion or production of the disease (Kahrs et al., 1980) and bovine leukemia virus (BLV) could not be transmitted via leucocyte-free semen from BLV-infected bulls (Kaja and Olson, 1982) .

There is a high demand by other countries for breeding material such as embryos and semen, from South African cattle (de la Rey, 2003, Kahrs et al., 1980). Artificial insemination particularly is an extremely effective means of disseminating genetic material and at present semen exports exceed embryo exports. Lumpy skin disease virus is one of the viruses, identified in semen risk analysis, as a potential hazard in the international movement of bovine semen (Hentzen, 2000). There is currently no published information on the ability of LSDV infected semen to establish clinical disease in cows naturally or artificially inseminated i.e. trans-uterine infection. Further no data is available on the effect of the use of infected semen for in vivo fertilisation of oocytes, or on the potential for spread of the disease to recipients of embryos produced in this way.

The objectives of the current study were therefore to assess the possibility of transmission of LSDV through semen and subsequent LSDV infection in cows and embryos.

\section{MATERIALS AND METHODS}

Animals: Thirteen (13) healthy thin-skinned European breed heifers from a diverse genetic pool were sourced from herds where LSD had not been seen for 3 years, and where no vaccination was practiced. Only animals tested negative for antibodies to LSDV by using the serum neutralisation test (SNT) were selected and kept at the insect-free stables of the Biological Research Centre of the University of Pretoria (UPBRC), Faculty of Veterinary Science.

The experiment was divided into two trials - each with one control animal. The two trials ran simultaneously, and were only denoted as two trials for simplification of the experimental design. 
Trial I investigated the possible effect of LSDV on embryo parameters in vivo. Heifers in this trial were called 'Embryo heifers'. Trial II investigated the response of heifers to insemination with semen spiked with an infective dose of LSDV. Heifers in this trial were called 'Al heifers'

The heifers were divided into groups of 6 (Embryo Group) and 7 animals (Al Group) each. Oestrus was synchronized in all heifers using the OvSynch protocol. Briefly this involved intramuscular injections of 100 microgram buserelin (Fertagy|®) on Day -10 , a luteolytic dose of prostaglandin F2a (Lutalyse $\AA$ ) on Day -3 , another injection of buserelin on Day -1 and insemination 17-24 hrs after the second buserelin injection. The day of insemination was denoted Day 0. Embryo heifers were superovulated using a single injection of pregnant mare serum gonadotropin (PMSG) on the day of the second buserelin injection (Pursley and Bello, 2007).

Lumpy skin disease virus preparation: A South African field isolate (V248/93) was used to spike semen as challenge material for experimental animals. The infectivity of the field isolate had previously been established (Tuppurainen et al., 2005). Bovine dermis cells prepared from a foetal calf's ear were cultured in $75 \mathrm{~cm}^{2}$ tissue culture flasks in Minimum Essential Medium (MEM) supplemented with L-glutamine (1 m// ) , 0,2 \% sodium bicarbonate (Highveld Biological), $5 \%$ foetal calf serum (Adcock Ingram) and $1 \mathrm{ml} / \ell$ gentamycin $(50 \mathrm{mg} / \mathrm{ml}$ Genta 50 Phenix). When $70-80 \%$ of the cell monolayer was confluent, a volume of $0.5 \mathrm{ml}$ of virus isolate was inoculated into $75 \mathrm{~cm}^{2}$ flask. Virus was harvested when $90-100 \%$ of the cell monolayer was infected and showed typical cytopathic changes. Culture flasks were frozen briefly at $-70^{\circ} \mathrm{C}$ and thawed and the flasks were shaken gently to release the cell-associated virus. The cell cultures were centrifuged at $2000 \mathrm{rpm}$ for $3 \mathrm{~min}$. The supernatant was removed and aliquoted in volumes of $1.8 \mathrm{ml}$ and $3.5 \mathrm{ml}$ in cryo tubes (Nunc, Amersham, Johannesburg) and stored as reference stock virus at $-70{ }^{\circ} \mathrm{C}$ until used. The reference stock virus was titrated on bovine dermis cells using 96-well microtitre plates, including the cell control. Cells were observed daily for CPE and the $\mathrm{TCID}_{50}$ of the virus was calculated using the method of Reed and Muench (1938).

Experimental challenge with spiked semen: On Day 0, 11 animals were inseminated with 1 $\mathrm{mL}$ of fresh semen spiked with $1 \mathrm{ml}$ of LSDV virus suspension. The titer of the virus used was $5.5 \log T C I D 50 / \mathrm{m} \ell$. A control in each group consisted of an animal inseminated with an equivalent dose of unspiked semen.

\section{Sample collection and Observation}

All animals were observed daily for habitus and development of clinical signs. Rectal temperature was taken twice daily. Blood samples were collected in EDTA and heparin from all animals on days 2, 6, 9, 12, 16, 20, 23 and 27 post infection (p.i.), and subjected to PCR 
and virus isolation. Serum samples were collected on days 9, 12, 16, 20, 23 and 27 p.i. and subjected to SNT.

On Day 6, the 5 treatment heifers and 1 control heifer (EM heifers) received epidural anaesthesia, an embryo flushing catheter was passed into the uterine horns alternately and the embryos were flushed from the horns with embryo flushing media. Before use, flushing media was confirmed free of bovine viral diarrhoea virus (BVDV) using a RT-nPCR (Qiagen Cador BVDV Type 1/2 real-time RT-PCR Kit, Qiagen, Germany). Embryos were washed as described in the Manual of the International Embryo Transfer Society (IETS) (Stringfellow and Seidel, 1998), and tested for the presence of LSDV by PCR. The samples that were positive by PCR were subjected to virus isolation. The Embryo heifers stayed in the experiment until Day 27, after which time they were removed.

On Day 28, ultrasound pregnancy diagnosis per rectum was performed on the Al heifers.

Pregnant heifers were retained until day 42 , but non-pregnant heifers were removed from the trial.

Laboratory testing: To detect the presence of LSDV DNA in EDTA blood samples, embryos, flushing media and organs, PCR was performed using the primers of Ireland and Binepal (1998). Virus isolation was done on bovine dermis cell monolayers according to the method described by Tuppurainen et al. (2005). To determine seroconversion a SNT was performed using a 96-well plate format according to the standard protocol of the Virology Section, Department of Veterinary Tropical Diseases, Faculty of Veterinary Science, University of Pretoria (OIE, 2010). Grading of embryos flushed from Embryo heifers was evaluated according to the guidelines of the Manual of the IETS (Stringfellow and Seidel, 1998). Electron microscopy was performed on skin lesions by the EM-Section, Faculty of Veterinary Science, University of Pretoria. Immunoperoxidase staining of the uterine tissues were done by the section of Pathology, Faculty of Veterinary Science, University of Pretoria.

\section{RESULTS}

Al heifers: In the Al group, 3 of the 7 animals tested positive for viral DNA in blood between 10 - 17 days p.i. and 5 animals had seroconverted by the end of the trial. The 3 clinically affected heifers in the Al group all showed severe clinical signs, especially affecting the reproductive tract. Due to extreme, nonresponsive stranguria and extensive necrosis of their caudal reproductive tracts, 2 of these heifers were humanely destroyed and post mortem examinations were performed. 
Embryo heifers: Embryos were harvested from 2 infected heifers and these embryos were positive for LSDV DNA by PCR. Virus could also be isolated from both embryos using cell cultures. Stepwise washing as per IETS guidelines rendered the embryos free of LSDV DNA (Stringfellow and Seidel, 1998). One heifer tested PCR positive and VI positive on Day 16 and Day 23 respectively, while the other heifer remained negative for the duration of the trial (Table 1). Neither PCR nor virus isolation could identify LSDV infection in the flushing media recovered from the other heifers. Three of the five experimental heifers in the EM group had seroconverted by the end of the trial (Table 1).

\begin{tabular}{|c|c|c|c|c|c|c|c|c|c|c|c|}
\hline \multicolumn{2}{|c|}{ Days post-infection } & 2 & 6 & 9 & 10 & 11 & 12 & $\overline{16}$ & 20 & 23 & 27 \\
\hline Group & Parameter & & & & & & & & & & \\
\hline \multirow[t]{5}{*}{ Al $(n=6)$} & Clinical signs & & & & 1 & 3 & 3 & 3 & 3 & 2 & 1 \\
\hline & $\mathrm{VI}^{*}$ & & & 1 & & & & & & & \\
\hline & $\mathrm{SNT}^{*}$ & & & & & & & & 5 & 4 & 4 \\
\hline & $\mathrm{PCR}^{*}$ & & & 1 & & & & 2 & & & \\
\hline & Death & & & & & & & & & 1 & 1 \\
\hline \multirow[t]{7}{*}{ EM $(n=5)$} & Clinical signs & & & & & 2 & 2 & 3 & 3 & 3 & 3 \\
\hline & VI blood & & & & & & & & & 1 & \\
\hline & PCR & & & & & & & 1 & & & \\
\hline & SNT & & & $1^{*}$ & & & & 1 & 2 & 2 & 3 \\
\hline & VI embryo & & 2 & & & & & & & & \\
\hline & PCR embryo & & 2 & & & & & & & & \\
\hline & Death & & & & & & & & & & \\
\hline
\end{tabular}

Table 1: Clinical and laboratory findings and the amount of animals in which a positive result was found

In all affected animals, 5 in total, the first clinical signs of LSD infection were visible 10 days after experimental infection (p.i.) in the form of a severely swollen vulva. Fever reactions appeared from 11 days p.i. and were accompanied by characteristic skin nodules. Generalised lymphadenopathy was observed from 13 days p.i. Severe generalised LSD could be seen in 3 of the heifers, mild LSD in another 2 heifers, while the other heifers showed no obvious clinical signs. None of the heifers were found to be pregnant when ultrasonographic examination was performed 28 days after Al. None of the control animals tested positive by PCR or had seroconverted by the end of the trial (Table 1)

Necropsy findings: Subacute to chronic-active, severe diffuse haemorrhagic, deeply necrotic to sloughing vulvovaginitis and metritis was observed macroscopically during necropsy. The ovaries appeared normal with follicles in different developmental stages visible. Microscopically, severe, multifocal thromboses with concurrent infarction, ischaemia and tissue devitalisation characterized the uterus. Severe vasculitis combined with a lymphoplasmacytic cell infiltrate was present. Immunoperoxidase staining of the uterine tissues revealed positive, red granular cytoplasmic staining with an apparent predilection for 
macrophages. Lumpy skin disease viral DNA and virus could be demonstrated by PCR and $\mathrm{VI}$ in the reproductive organs (excluding ovaries) of both heifers. Transmission electron microscopy demonstrated LSD virus in skin samples.

\section{DISCUSSION}

The risk of transmitting LSDV via semen is not only a major concern for mainly the export industry in South Africa, but determining the presence of the virus in semen, will shed light on the epidemiology of the disease. The persistent shedding of LSDV in the semen of infected bulls was described by both Irons et al. (2005) and Tuppurainen et al. (2005), while the presence of viral DNA was demonstrated in all fractions of semen and in sheath wash samples from bulls that were shedding virus in semen for protracted periods of time (Annandale et al., 2010). This trial is the first experimental demonstration of seminal transmission of LSDV in heifers, thereby confirming the biosecurity risk posed by semen infected with LSDV.

Although many viruses are known to be shed in the semen of bulls (Afshar and Eaglesome, 1990), the true significance of the presence of virus in semen seems unclear. Burgess (1973) inseminated heifers with bovine ephemeral virus and failed to produce clinical disease, but did manage to show the development of antibodies two weeks after insemination. Similarly, Kupferschmied (1986) demonstrated humoral immunity subsequent to Al with semen spiked with bovine herpesvirus-1 but was only able to induce very slight clinical signs of infectious bovine rhinotracheitis (IBR). Seminal transmission of bovine viral diarrhea virus (BVDV) was demonstrated, as well as foetal infection via placental circulation (Meyling and Jensen, 1988). Reports of persistently infected calves following insemination with BVDV-infected semen (Niskanen et al., 2002) supports the epidemiological role of BVDV in the spread of the disease and justifies the control measures that are in place.

In the current trial, seroconversion could be demonstrated in 8 of the 11 heifers inseminated with semen spiked with LSDV. Taking into consideration the relatively high infective dose used to spike the semen, it may have lead to overstatement of the role of humoral immunity in LSDV infection in the current trial. Babiuk et al. (2008) established that the shedding of LSDV is low in bodily secretions (semen was not investigated specifically) and that the highest concentration of viral particles could be found in skin lesions. We postulate therefore that it is unlikely that similar infection rates would be achieved in herds where natural mating takes place or in herds where $\mathrm{Al}$ is practiced, considering the lower expected infective dose. The natural infective dose in semen still remains to be established. Serologically, the detection of a SNT positive sample on day 9 p.i. is unusual. Irons (2005) detected the first SNT positive 
sample on day 12 p.i. Possible explanations for the difference in results of the two trials could be the higher viral load used in the current trial and the intra-uterine route of infection, allowing different exposure to the immune system than the intravenous or intradermal route of infection.

The low pregnancy rates in this trail are noteworthy. While the exact reason for this was not investigated, the effect of viraemia or a direct virus effect can not be excluded.

Necropsy results are similar to what has been previously reported in the literature (Nagi, 1990, Annandale et al., 2010, Prozesky and Barnard, 1982). In the current trial, LSD skin lesions seemed less severe. However, lesions on mucous membranes, especially of the conjunctiva, nose, mouth and reproductive tract seemed more pronounced than what is normally seen in the field (Coetzer, 2004). The difference in severity of clinical disease between the Al group and ET group suggests that embryo flushing on Day 6 had a protective effect on the reproductive tracts of the heifers in the ET group. Of the two animals that were necropsied, the one had outspoken necrosis in the entire reproductive tract while the other one had only vaginal and vestibular necrosis. This finding might indicate that the clinical signs associated with LSDV infection via natural mating may differ from Al, since the cervix serves as a natural barrier during natural mating. This finding warrants further investigation. It has to be noted though that the small number of experimental animals in this trial precludes statistical analysis and definitive conclusions.

The current study confirms transmission of LSDV to heifers and embryos through artificial insemination. The high titre of virus used to spike semen in the current trial precludes conclusions on the quantification of the biosecurity risks associated with the presence of LSDV in bovine semen under field conditions. Further studies are indicated to investigate the biosecurity risk under field conditions. A further suggestion that the course of clinical LSDV infection mirrors the route of infection similarly warrants investigation.

\section{ACKNOWLEDGEMENTS}

This project was funded by the NRF. Project number FA 200704250000

\section{REFERENCES}

Afshar, A. and M. D. Eaglesome, 1990: Viruses associated with bovine semen. Veterinary Bulletin, 60, 93-109. 
Aiel, 2009: Lumpy skin disease. Bovine and Ovine Magazine, 67, 22-24.

Ali, B. H. and H. M. Obeid, 1977: Investigation of the first outbreaks of lumpy skin disease in the Sudan. British Veterinary Journal, 133, 184-189.

Annandale, C. H., P. C. Irons, V. P. Bagla, U. I. Osuagwuh and E. H. Venter, 2010: Sites of persistence of lumpy skin disease virus in the genital tract of experimentally infected bulls. Reproduction in Domestic Animals, 45, 250-255.

Babiuk, S., T. R. Bowden, G. Parkyn, B. Dalman, L. Manning, J. Neufeld, C. Embury-Hyatt, J. Copps and D. B. Boyle, 2008: Quantification of lumpy skin disease virus following experimental infection in cattle. Transboundary and Emerging Diseases, 55, 299-307.

Burgess, G. W., 1973: Attempts to infect cattle with bovine ephemeral fever by inoculation of virus into the cervix. Australian Veterinary Journal, 49, 341-343.

Carn, V. M. and R. P. Kitching, 1995: An investigation of possible routes of transmission of lumpy skin disease virus (Neethling). Epidemiology and Infection, 114, 219-226.

Chihota, C. M., L. F. Rennie, R. P. Kitching and P. S. Mellor, 2001: Mechanical transmission of lumpy skin disease virus by Aedes aegypti (Diptera: Culicidae). Epidemiology and Infection, 126, 317-321.

Chihota, C. M., L. F. Rennie, R. P. Kitching and P. S. Mellor, 2003: Attempted mechanical transmission of lumpy skin disease virus by biting insects. Medical and Veterinary Entomology, 17, 294-300.

Christopher-Hennings, J., E. A. Nelson, R. J. Hines, J. K. Nelson, S. L. Swenson, J. J. Zimmerman, C. L. L. Chase, M. J. Yaeger and D. A. Benfield, 1995: Persistence of porcine reproductive and respiratory syndrome virus in serum and semen of adult boars. Journal of Veterinary Diagnostic Investigation, 7 , 456-464.

Coetzer, J. A. W., 2004: Lumpy skin disease. In: J. A. W. Coetzer and R. C. Tustin (eds), Infectious diseases of livestock. Volume Two, 2 edn., pp. 1268-1276. Oxford University Press.

de la Rey, R., 2003: Welcoming address. South African Veterinary Semen and Embryo Group of the South African Veterinary Assocaition.

Guthrie, A. J., P. G. Howell, J. F. Hedges, A. M. Bosman, U. B. R. Balasuriya, W. H. McCollum, P. J. Timoney and N. J. MacLachlan, 2003: Lateral transmission of equine arteritis virus among Lipizzaner stallions in South Africa. Equine Veterinary Journal, 35, 596-600. 
Hentzen, A., 2000: Bovine Semen Risk Analysis: Report to South African Veterinary Semen and Embryo Group of the South African Veterinary Association.

Ireland, D. C. and Y. S. Binepal, 1998: Improved detection of capripoxvirus in biopsy samples by PCR. Journal of Virological Methods, 74, 1-7.

Irons, P. C., 2008: The bull as a source of pathogens: A Southern African perspective. Utrecht University.

Irons, P. C., E. S. M. Tuppurainen and E. H. Venter, 2005: Excretion of lumpy skin disease virus in bull semen. Theriogenology, 63, 1290-1297.

Jordan, H. L., J. Howard, R. K. Sellon, D. E. Wildt, W. A. Tompkins and S. Kennedy-Stoskopf, 1996: Transmission of feline immunodeficiency virus in domestic cats via artificial insemination. Journal of Virology, 70, 8224-8228.

Kahrs, R. F., E. P. J. Gibbs and R. E. Larsen, 1980: The search for viruses in bovine semen, a review. Theriogenology, 14, 151-165.

Kaja, R. W. and C. Olson, 1982: Non-infectivity of semen from bulls infected with bovine leukosis virus. Theriogenology, 18, 107-112.

Kitching, R. P. and P. S. Mellor, 1986: Insect transmission of capripoxvirus. Research in Veterinary Science, 40, 255-258.

Kitching, R. P. and W. P. Taylor, 1985: Transmission of capripoxviruses. Research in Veterinary Science, 39, 196-199.

Kupferschmied, H. U., U. Kihm, P. Bachmann, K. H. Müller and M. Ackermann, 1986: Transmission of IBR/IPV virus in bovine semen: a case report. Theriogenology, 25, 439-443.

Meyling, A. and A. M. Jensen, 1988: Transmission of bovine virus diarrhoea virus (BVDV) by artificial insemination (Al) with semen from a persistently-infected bull. Veterinary Microbiology, 17, 97-105.

Nagi, A. A., 1990: Lumpy skin disease: Cutaneous and testicular lesions. Assiut Veterinary Medical Journal, 23, 90-99. 
Niskanen, R., S. Alenius, K. Belák, C. Baule, S. Belák, H. Voges and H. Gustafsson, 2002: Insemination of susceptible heifers with semen from a non-viraemic bull with persistent bovine virus diarrhoea virus infection localized in the testes. Reproduction in Domestic Animals, 37, 171-175.

OIE, 2010: Manual of Diagnostic Tests and Vaccines for Terrestrial animals. Chapter 2.4.14, Lumpy Skin Disease. Paris.

Prozesky, L. and B. J. H. Barnard, 1982: A study of the pathology of lumpy skin disease in cattle. Onderstepoort J Vet Res, 49, 167-175.

Pursley, J. R. and N. M. Bello, 2007: Ovulation synchronisation strategies. In: R. S. Youngquist and W. R. Threlfall (eds), Current therapy in Large Animal Tehriogenology, 2nd edn., pp. 287-293. Saunders Elsevier, St. Louis, Missouri.

Reed, L. J. and H. Miuench, 1938: A simple method of estimating fifty per cent endpoints. American Journal of Hygiene, 27, 493-497.

Smit, A. J. d., A. Bouma, C. Terpstra and J. T. v. Oirschot, 1999: Transmission of classical swine fever virus by artificial insemination. Veterinary Microbiology, 67, 239-249.

Stringfellow, D. A. and S. M. Seidel, 1998: Manual of the International Embryo Transfer Society, 3rd edn. IETS, Savoy, Illinois.

Tuppurainen, E. S. M. and C. A. L. Oura, 2012: Review: Lumpy Skin Disease: An Emerging Threat to Europe, the Middle East and Asia. Transboundary and Emerging Diseases, 59, 40-48.

Tuppurainen, E. S. M., W. H. Stoltsz, M. Troskie, D. B. Wallace, C. Oura, P. S. Mellor, J. A. W. Coetzer and E. H. Venter, 2010: A potential role for hard (ixodid) tick vectors in the transmission of lumpy skin disease virus in cattle. Transboundary and Emerging Diseases, 58, 93-104.

Tuppurainen, E. S. M., E. H. Venter and J. A. W. Coetzer, 2005: The detection of lumpy skin disease virus in samples of experimentally infected cattle using different diagnostic techniques. Onderstepoort Journal of Veterinary Research, 72, 153-164.

Woods, J. A., 1988: Lumpy skin disease virus - A review. Tropical Animal Health and Production, 20, 11-17. 